\title{
Wheat Preservation Using Electric Field
}

\author{
D. K. Chaturvedi* \\ Department of Electrical Engineering, Faculty of Engineering, \\ Dayalbagh Educational Institute, Dayalbagh, Agra 282005, India \\ *Corresponding author
}

\section{A B S T R A C T}

\section{Keywords}

Preservation,

Electric field,

Temperature,

Moisture

Article Info

Accepted:

15 December 2019

Available Online:

20 January 2020
Large amount of wheat grains wasted during preservation. This paper deals with an high voltage electric field (HVEF) preservation method for wheat grain. The HV upto $50 \mathrm{kV}$ is given in pulses between two electrodes and wheat grain is kept in between them to increase its shelf life. The wheat is spoiled during storage, fungi crop during harvesting, transport, and handling operations. The temperature and moisture content during storage are major factors to spoil it and germinate insects and fungal growth. This HVEF remove the moisture content and avoid fungal growth.

\section{Introduction}

The wheat crop cultivated in India is a major Rabi crop on approximately 30 million hectares [1]. Maximum area under wheat is in India $(14 \%)$, followed by Russia $(12.43 \%)$, China $(11.14 \%)$ and the USA $(6.90 \%)$ which altogether accounts for about $45 \%$ of global area. Annual grain production in 2018 was approximately 270 million tonnes in India [2]. The history of wheat production is shown in Fig. 1 and Table 1. Availability of Food grains per capita is given in Table 2 . China is the major producer of wheat followed by India, Russia and the USA. Whatever the wheat grains produced in agricultural field does not reach to the end users or consumers, but some of the wheat grains are lost. The wheat losses can be classified in two stages; namely, pre-harvesting loss and post harvesting loss. The pre-harvesting losses are pre-matured or delayed harvesting of crop, eating of birds and animals etc. The post harvesting losses include transportation loss, threshing loss and preservation loss. The preservation losses are the losses due to insect-pests, rats, fungus and rodent attack. The records shows that India's food wastage is approximately 1.83 Lakh ton in last five years, which is ruined. According to official data released by the Ministry of Consumer Affairs, almost 62,000 tonnes of food grain was damaged in FCI warehouses between 2011 and 2017. The Institution of Mechanical 
Engineers (IME) report on food wastage in global prospective tells that $50 \%$ of food produced not accessible by human [3]. Total annual shortage is 14-15 million tones. Food grain wastage year-wise and state-wise are given in Table -3 . To reduce post harvest preservation losses a number of methods are suggested in the past such as dry up the wheat grains to reduce moisture content less than $10 \%$, use chemicals, store in airtight compartment, use Leaves of Neem or its seed powder etc. All these methods affect the quality of wheat grain and chemicals (Celphos tablets dibromide, methylene) are injurious to health. Hence in this paper, a electric high voltage preservation system is proposed.

According to an estimate by the World Food Program, one quarter of the world's hungry live in India. India ranks 66th in the world in battling hunger. Over 20 crore people are hungry. During 1997-2007, 10 lakh tonnes of food grain was damaged. With this 10 lakh tonnes of food one crore people could be fed for a year. At a time when food prices are sky-rocketing and thousands of families living below poverty line are struggling to get their meals, such wastage of food grain is unfortunate and shameful.

In this paper, High Voltage Electric Field (HVEF) method is proposed to preserve it effectively. The paper is divided in five sections, first section deals the introduction of paper. Second section mentions the major factors for wheat rottening and then it discusses the method for protecting it from HVEF.

\section{Major factors for wheat rottening}

\section{Biotic factors}

Insects:

1) Khapra beetle
2) Lesser grain borer

3) Red flour beetle

4) Weevils

Moulds

Birds

Rats

\section{Environmental factors}

\section{Temperature}

Humidity

According to PANSAY committee $9.3 \%$ of wheat goes in post harvest losses. Out of which: Storage loss-6.6\%. The percentage estimated storage loss of food grain given in Table 4.

In this paper, wheat preservation is done by HVEF which includes the effect of high electric field on weevils. we examined a sample of wheat under a high voltage pulse generator and a study was done to find the optimum working value of electric field.

\section{HVEF method of preservation}

The main cause of weevils' attack is the moisture content in the wheat. Paramagnetic material present in the wheat is moisture and weevil is also a paramagnetic material whereas wheat is a diamagnetic material. So, when we apply voltage across electrodes current flows through only paramagnetic material on the other hand, when we apply voltage across a dielectric material some amount of heat is produced which helps to dry the wheat and reduces the moisture content in the wheat. So wheat is now preserved from weevils because moisture is present in the wheat is minimum.

$P=2 \pi \cdot f \cdot \varepsilon_{0} \cdot \varepsilon^{\prime} \cdot \tan (\delta) \cdot E\left[\mathrm{~W} / \mathrm{m}^{3}\right]$

$f:$ the frequency of the electrical field $[\mathrm{Hz}]$

$\varepsilon_{0}$ : the dielectric constant of vacuum 
$(8.84 \cdot 10-12 \mathrm{~F} / \mathrm{m})$

$\varepsilon^{\prime} \cdot \tan (\delta)$ : the loss factor of the material

$\mathrm{E}:$ the electrical field strength in the material (rms) $[\mathrm{V} / \mathrm{m}]$

Experimental set up is shown in Fig. 2.

Specification of equipment used in schematic diagram shown in Fig. 3.

1) Step-up $100 \mathrm{Kv}$ transformer

2) $1000 \mathrm{pF} 100 \mathrm{Kv}$ capacitor

3) Treatment chamber

4) Different shapes of electrodes (e.g. spherical, point, plate etc.)

\section{Experimentation}

The experimentation on wheat grains is done under different :
a) Shape of Electrode
b) Pressure of Air
c) Moisture Content
d) duty cycle

\section{Model designing}

Now we want to design a model which fulfill our needs for that we fabricated it in the three stages:-

\section{First stage model}

The objective of this model is to test whether our selected material is able to withstand that much high voltage or not, for that we take up one $500 \mathrm{ml}$ plastic bottle and made two holes in it and fix two pencil cell graphite electrode in it and connected it with high voltage generator.

We gradually increased the voltage with the help of high voltage generator and we were surprised that it can withstand very high voltage of $13 \mathrm{KV}$ and then breakdown of air takes place inside the bottle.

\section{Medium stage model}

The objective of this model was to fabricate the actual prototype of high voltage generator in which we vary the electric field by varying distance in between the electrodes for that we fabricated a small wooden box in which on both the sides we made holes for pencil cell size electrode. On one side of box we made only one hole and on the other side of box we made various holes at different distances so with the help of it we changed the spacing in between the electrodes and also measured the breakdown voltage.

\section{Final stage model}

The objective of this model was to fabricate the medium stage model on to the bigger scale for that we designed a wooden box of dimensions:
a) Length:- $50 \mathrm{~cm}$
b) Breadth:- $35 \mathrm{~cm}$
c) Height:- $12.5 \mathrm{~cm}$

In this, one side is fixed while other side of box is moveable and on both the sides graphite electrode are mounted having the dimensions:-
a) Length:- $26.5 \mathrm{~cm}$
b) Breadth:- $10 \mathrm{~cm}$
c) Height:- $3 \mathrm{~cm}$

So that in this model we can change distance in between the electrodes and having different magnitude of electric field in which we can treat our grains.

\section{Treatment of Grains}

Then we treated the sample of grains by applying different magnitude of electric field and observed the changes in the sample of wheat. Table 5 shows the different magnitude of electric field which can be applied on the sample of wheat for how much duration and 
what is the effect observed on the sample of wheat.

So, as one can see that maximum and favorable effect is seen at a electric field of magnitude of $3.57 \mathrm{Kv} / \mathrm{cm}$ and the duration of pulses is dependent upon the consumer which knows how much risk factor is there for the attack of weevils on wheat.

\section{Observation}

When the treated wheat grain bag is opened weevils are in the hurry to leave the sample pack and within no time all the weevils left sample of wheat bag and now it is weevil free. Hence it can be concluded that when HVEF is applied to the infected samples and after some iterations of treatments, weevils are leaving the grains. So if we repeatedly apply the HVEF impulses to the wheat then weevils will not attack the sample of wheat and our grains are preserved.

The experiments are also repeated for fresh wheat grains in which no weevils are present and this process reduce the moisture content present in the sample and as it is very clear that the weevils' attack is due to the moisture present, so on fresh grains we apply different magnitude of HVEF and find that after some number of treatments the moisture content is reduced so that probability of attack by weevils is depreciated significantly. So with the help of this setup we can preserve fresh grain as well as we can treat the infected grains by removing the weevils form sample of wheat.

Table.1 History of Wheat production

\begin{tabular}{|l|c|}
\hline Years & Wheat Production in mt \\
\hline 1960- 61 & 11 \\
\hline $\mathbf{1 9 7 0}-\mathbf{7 1}$ & 23.83 \\
\hline $\mathbf{1 9 8 0}-\mathbf{8 1}$ & 36.31 \\
\hline $\mathbf{1 9 9 0 - 9 1}$ & 55.14 \\
\hline $\mathbf{2 0 0 0}-\mathbf{0 1}$ & 69.68 \\
\hline $\mathbf{2 0 1 0}-\mathbf{1 1}$ & 86.87 \\
\hline $\mathbf{2 0 1 4}-\mathbf{1 5}$ & 86.53 \\
\hline $\mathbf{2 0 1 5}-\mathbf{1 6}$ & 92.29 \\
\hline $\mathbf{2 0 1 6}-17$ & 98.51 \\
\hline $\mathbf{2 0 1 7}-18$ & 99.7 \\
\hline
\end{tabular}

Table.2 Availability of Food grains per capita (kg/capita) [4]

\begin{tabular}{|l|l|l|l|l|l|l|l|}
\hline Years & Rice & Wheat & $\begin{array}{l}\text { Other } \\
\text { Cereals }\end{array}$ & $\begin{array}{l}\text { Total } \\
\text { Cereals }\end{array}$ & Gram & $\begin{array}{l}\text { Total } \\
\text { pulses }\end{array}$ & $\begin{array}{l}\text { Food } \\
\text { grains }\end{array}$ \\
\hline $\mathbf{1 9 5 1}$ & 58.0 & 24.0 & 40.0 & 122.0 & 8.2 & 22.1 & 144.1 \\
\hline $\mathbf{1 9 6 1}$ & 73.4 & 28.9 & 43.6 & 145.9 & 11.0 & 25.2 & 171.1 \\
\hline $\mathbf{1 9 7 1}$ & 70.3 & 37.8 & 44.3 & 152.4 & 7.3 & 18.7 & 171.1 \\
\hline $\mathbf{1 9 8 1}$ & 72.2 & 47.3 & 32.8 & 152.3 & 4.9 & 13.7 & 166.0 \\
\hline $\mathbf{1 9 9 1}$ & 80.9 & 60.0 & 29.2 & 171.0 & 4.9 & 15.2 & 186.2 \\
\hline $\mathbf{2 0 0 1}$ & 69.5 & 49.6 & 20.5 & 141.0 & 2.9 & 10.9 & 151.9 \\
\hline $\mathbf{2 0 0 5}$ & 64.7 & 56.3 & 21.7 & 142.7 & 3.9 & 11.5 & 154.2 \\
\hline $\mathbf{2 0 0 9}$ & 68.8 & 56.5 & 23.3 & 148.6 & 4.7 & 13.5 & 162.1 \\
\hline
\end{tabular}

Source: Directorate Economics and Statistics, Department of Agriculture and Cooperation 
Table.3 Food grain wastage year-wise and state-wise

\begin{tabular}{|c|c|}
\hline \multicolumn{2}{|c|}{ Foodgrain wastage } \\
\hline Year & $\begin{array}{c}\text { Quantity } \\
\text { (In tons) }\end{array}$ \\
\hline $2013-14$ & 24695.5 \\
\hline $2014-15$ & 18847.2 \\
\hline $2015-16$ & 3115.7 \\
\hline $2016-17$ & 8775.6 \\
\hline $2017-18$ & 2244.74 \\
\hline Maximum wastage \\
\hline West Bengal & 12,670 \\
\hline Maharashtra & 9,370 \\
\hline Odisha & 8,219 \\
\hline Bihar & 6,184 \\
\hline Andhra Pradesh & 4,944 \\
\hline
\end{tabular}

Table.4 Estimated Storage Loss (\%) of Food-grains

\begin{tabular}{|l|l|l|l|l|}
\hline Cause & Farm level & Trade & Public Agencies \\
\hline Insects & 3.4 & & Sheds & Silos \\
\hline Rodents & $0.5-1.0$ & 3.4 & $0.5-1.0$ & 0.5 \\
\hline Birds & Neg. & $0.3-1.0$ & Neg. & Nil \\
\hline Moisture & Neg. & 0.2 & 0.2 & Nil \\
\hline Others & - & 0.2 & 0.2 & 0.2 \\
\hline Total & $\mathbf{5}$ & 0.3 & 0.3 & Neg. \\
\hline
\end{tabular}

Table.5 Different HVEF and duty cycle

\begin{tabular}{|l|l|l|l|}
\hline Voltage(kV) & Electric field(kV/cm) & \multicolumn{1}{|c|}{$\begin{array}{c}\text { Time(sec)/ } \\
\text { Time gap }\end{array}$} & Effect \\
\hline $\mathbf{2 7}$ & 3.375 & $30 / 60$ & No change \\
$\mathbf{2 4}$ & 3 & $30 / 60$ & \\
$\mathbf{2 3}$ & 2.875 & $30 / 60$ & \\
\hline $\mathbf{2 6}$ & 3.714 & $60 / 120$ & Hissing sound \& weevils leaving \\
$\mathbf{2 4 . 5}$ & 3.5 & $60 / 120$ & grains \\
$\mathbf{3 0}$ & 4.28 & $60 / 120$ & \\
\hline $\mathbf{2 5}$ & 3.57 & $240 / 480$ & Hissing sound increases \& \\
$\mathbf{2 5}$ & 3.57 & $300 / 600$ & weevils leaving grains \\
\hline $\mathbf{2 5}$ & 3.57 & $300 / 600$ & Hissing sound \& weevils leaving \\
$\mathbf{2 5}$ & 3.57 & $300 / 600$ & grains \\
\hline
\end{tabular}


Fig.1 Quinquennial scenario in area, production and yield of wheat [2]

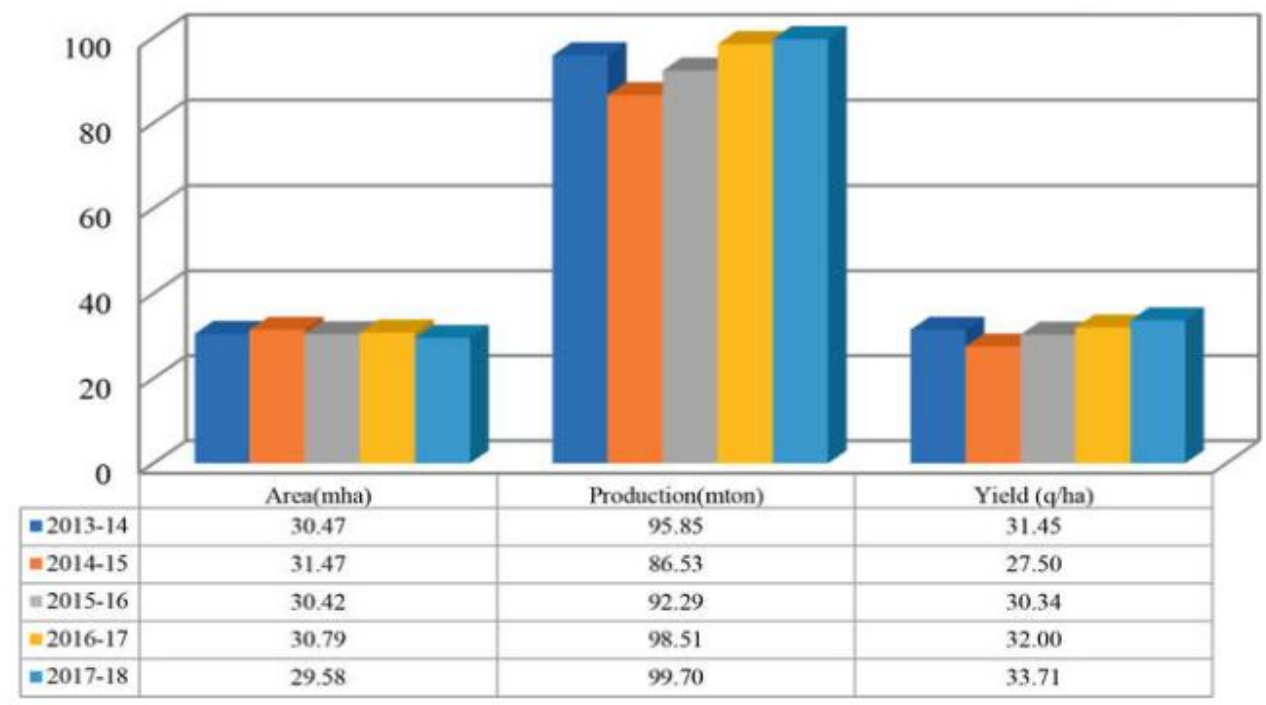

Fig.2 HVEF experimental setup

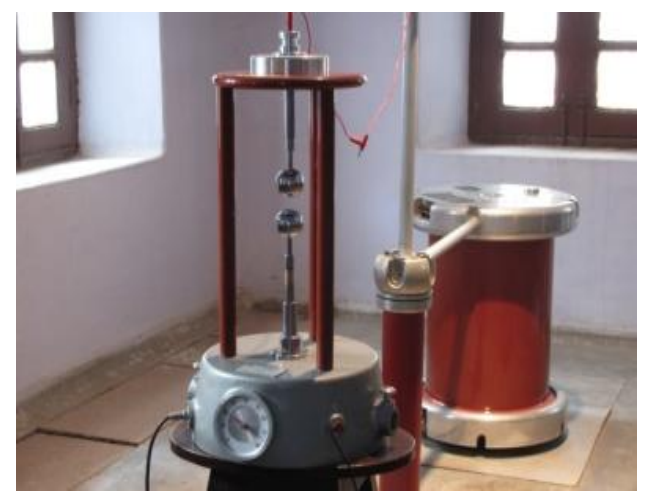

Fig.3 The Schematic diagram

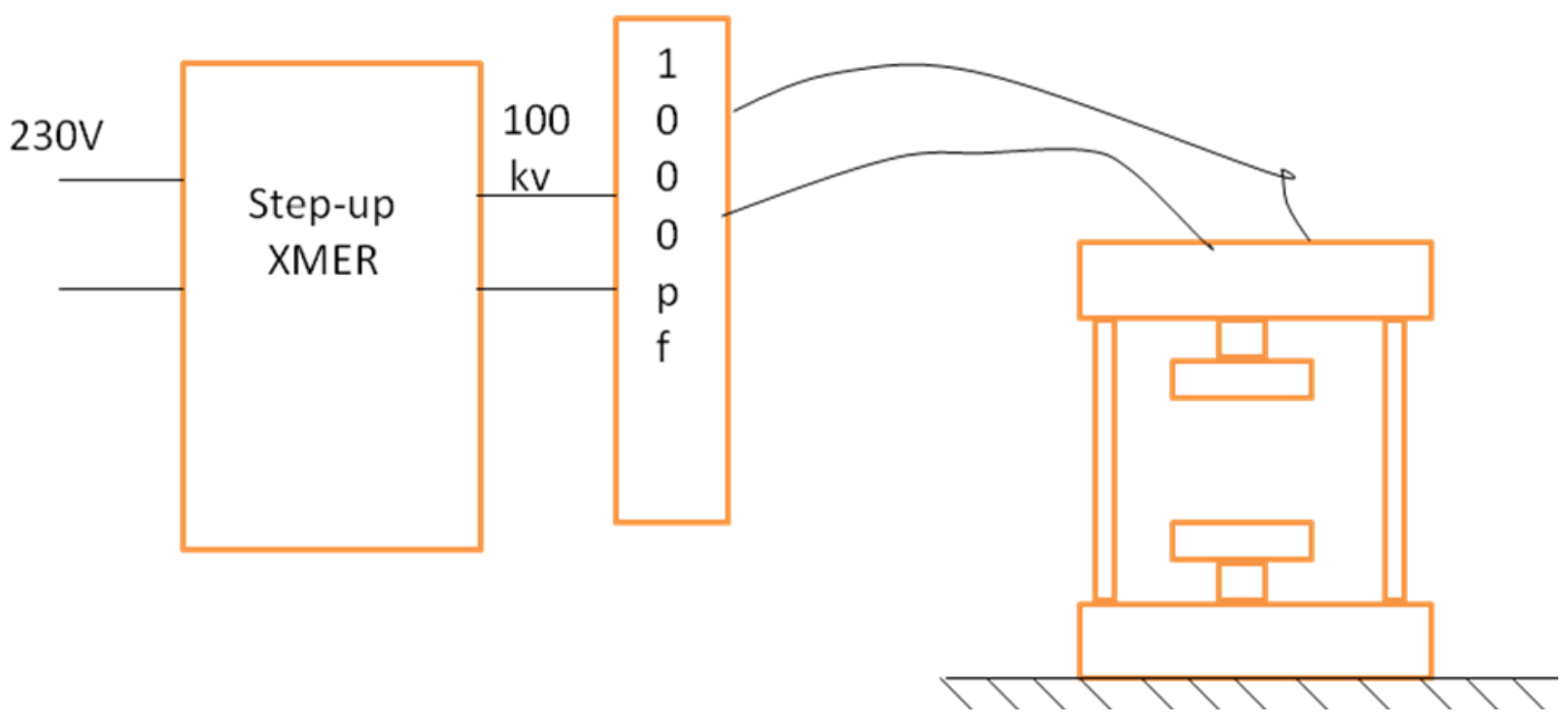


Fig.4 Small scale model

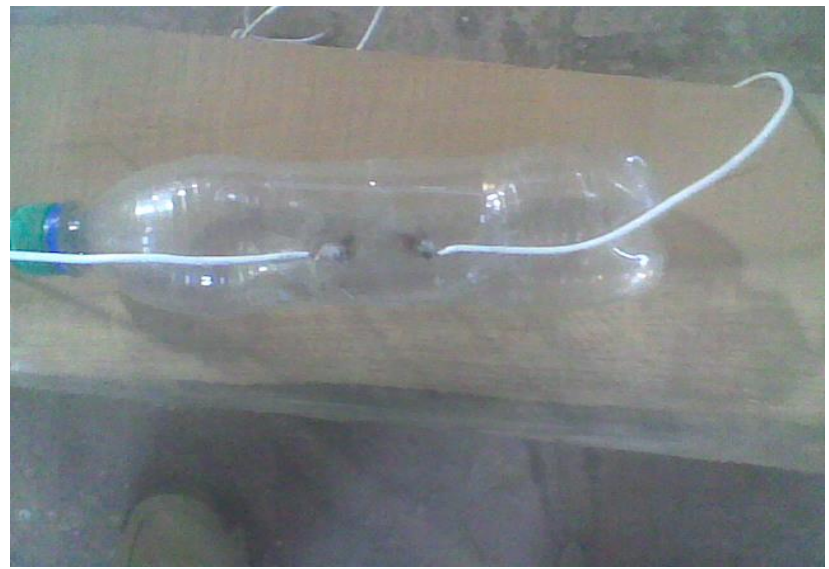

Fig.5 sample under test in high voltage generator

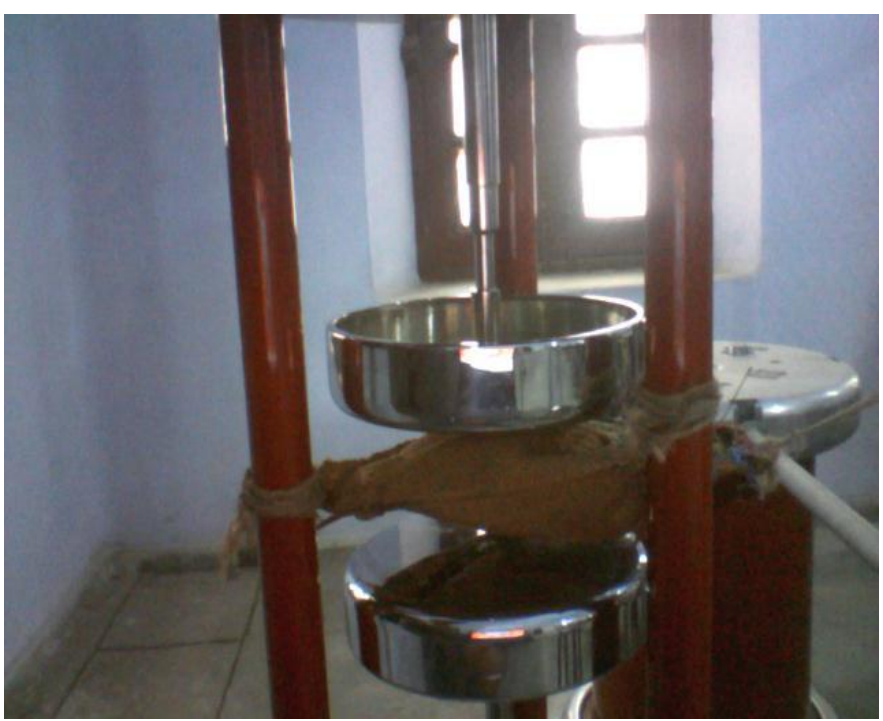

Fig.6 final stage model

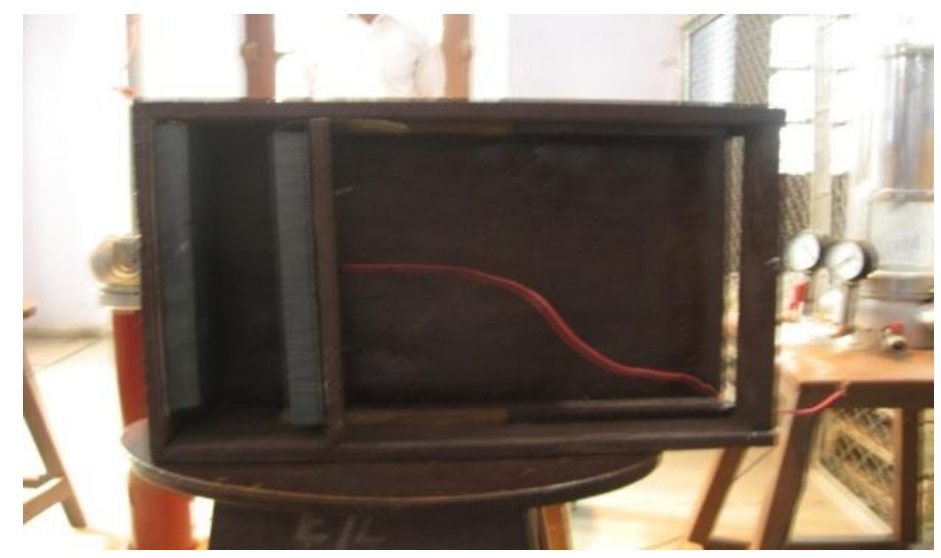


Fig.7 Treated grains in which weevils is trying to come out from grains which is encircled by the red circle

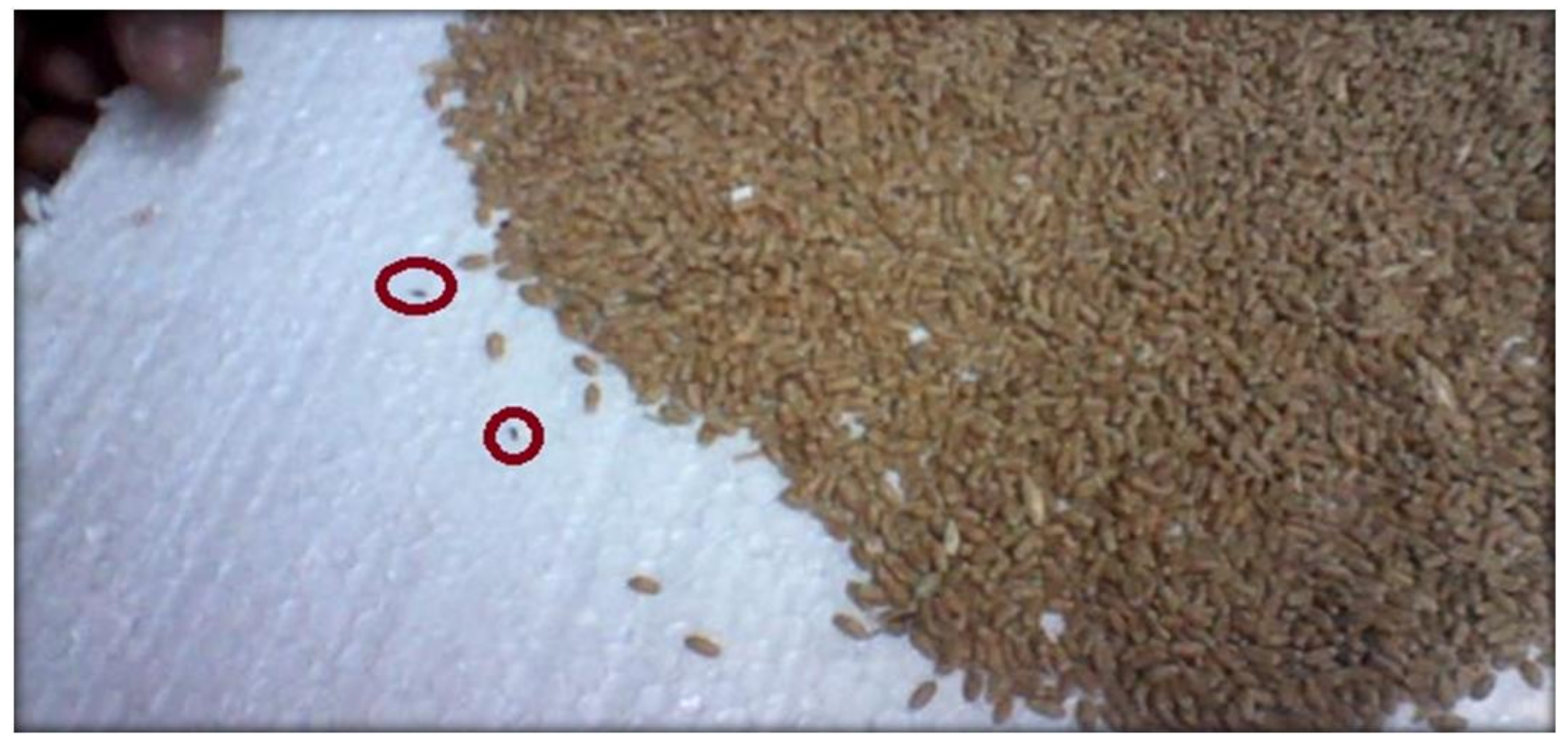

We observed the movement of weevils under microscope and saw that weevils were trying to leave the grains and with in no time weevils are out of the sample of wheat.

Conclusion and future scope of the study are as follows:

The wheat grain loss during preservation is an important problem in our country. In this paper HVEF method is used to minimize this loss and increase Shelf life of wheat. At the same time moisture content of wheat is also reduced. Weevils leave the sample under test when HVEF is applied. The further studies may be carried out to design a HV high frequency set up to effectively protect the wheat grain during storage.

\section{References}

1. Veena Kumari and Rakesh Kumar Prasad, An Analysis of Production and Consumption Pattern in India, International Journal of Current Microbiology and Applied Sciences
ISSN: 2319-7706 Special Issue-7 pp. 3923-3931.

2. Sendhil Ramadas, T.M. Kiran Kumar and Gyanendra Pratap Singh (July 12th 2019). Wheat Production in India: Trends and Prospects [Online First], IntechOpen,

DOI: 10.5772/intechopen.86341. Available from: https://www.intechopen.com/onlinefirst/wheat-production-in-india-trendsand-prospects.

3.http://timesofindia.indiatimes.com/articlesh ow/17969340.cms?utm_source=content ofinterest\&utm_medium=text\&utm_ca mpaign $=$ cppst

4. https://www.newindianexpress.com/ thesundaystandard/2018/mar/25/graindrain-1791998.html

5. Payne, T. S. (2002). Harvest and storage management of wheat. In B. C. Curtis, S. Rajaram, \& H. G. Macpherson (Eds.), Bread wheat: Improvement and production. FAO plant production and protection series no. 30. Rome: Food and Agriculture Organization of the United Nations. 
6. Abdullahi, A. \& Haile, A. 1991. Research on the control of insect and rodent pests of wheat in Ethiopia. In Wheat research in Ethiopia: a historical perspective. Addis Ababa, IAR/CIMMYT.

7. Appert, J. 1987. The storage of food grains and seeds. London, Technical Centre for Agricultural and Rural Cooperation (CTA), MacMillan Education.

8. Chunni, R. \& Singh, V.S. 1996. Resistance to Sitophilus oryzae in wheat and associated grain characteristics. Ind. $J$. Entomol., 58(1): 79-90.

9. Czarnecki, E. \& Evans, L.E. 1986. Effect of weathering during delayed harvest on test weight, seed size and grain hardness of wheat. Can. J. Plant Sci., 66: 473482.

10. Ignatowicz, S. \& Wesolowska, B. 1996. Repellency of powdered plant material of the Indian neem tree, the Labrador tea, and the sweet-flat, to some stored product pests. Polskie-Pismo Entomologiczne, 65(1-2): 61-67.

11. Zewar, M.M. 1993. The use of high temperatures for disinfesting wheat from Sitophilus granarius L., and cowpea from Callosoruchus maculatus (F.). Egyp. J. Agric. Res., 71(3): 671-67

12. Mishenko $\mathrm{AA}^{1}$, et.al.., Complex highfrequency technology for protection of grain against pests. J Microw Power Electromagn Energy. 2000;35(3):17984.

13. Rashkovan VM, et.al. Interaction of electromagnetic waves with granular agricultural product and insects. $J$ Microw Power Electromagn Energy. 2003; 38(4):225-35.

\section{How to cite this article:}

Chaturvedi, D. K. 2020. Wheat Preservation Using Electric Field. Int.J.Curr.Microbiol.App.Sci. 9(01): 1861-1869. doi: https://doi.org/10.20546/ijcmas.2020.901.208 